Original Article

\title{
KNOWLEDGE OF WOMEN ON EARLY SYMPTOMS OF CANCER IN RURAL AND URBAN AREAS OF M ANGALORE
}

\author{
Sonia Jacob' ${ }^{1}$, Fatima D'Silva ${ }^{2}$ \\ ${ }^{1}$ Assistant Professor, Pariyaram College of Nursing, Kerala, \\ ${ }^{2}$ Principal, Nitte Usha Institute of Nursing Sciences, Nitte University, Deralakatte, M angalore \\ Correspondence : \\ Fatima D'Silva \\ Principal, Nitte Usha Institute of Nursing Sciences, Nitte University, Deralakatte, Mangalore \\ E-mail : ftds_1970@ rediffmail.com
}

\begin{abstract}
:
A descriptive cross sectional survey design was adopted for the study to assess and compare the level of knowledge of women on early symptoms of cancer. The sample consisted of 200 women, 100 from urban area of Jeppu and 100 from rural area of Natekal PHC. Stratified Sampling technique was used for selection of the samples. The data was collected by a demographic pro forma and a knowledge questionnaire which consisted of 23 multiple choice and 11 dichotomous (Yes/No) questions.Reliability of the tool was assessed using split half method and the reliability coefficient wasfound to be 0.9 .

Though the overall knowledge score of urban women was comparatively higher (38.26) than their rural counterparts (34.79), It was encouraging to note that rural women (53.6\%) had better knowledge regarding risk factors and etiology of cancer when compared to urban women (51.02\%).

In India cancer related mortality is very high due to lack of awareness of the early symptoms leading to delayed screening and increased exposure rate of the risk factors. Nurses play a significant role in the disease prevention and health promotion of patients with cancer. Educational programs on healthful living with cost effective and motivating teaching strategies can be undertaken for the community so as to curb the mortality and morbidity associated with cancer
\end{abstract}

Keywords: Knowledge, Women, Early symptoms of cancer

\section{Introduction :}

Cancer is one of the major diseases all over the world and an important factor in the global burden of disease in the decades to come. Approximately 10 million people are diagnosed with cancer every year and more than 6 million die of the disease each year.

Accounting for $12 \%$ of all deaths, cancer is one of the major causes of mortality all over the world. The estimated number of new cases each year is expected to rise from 10 million in 2000 to 15 million by 2020 . Some $60 \%$ of all these new cases will occur in the less developed parts of the world ${ }^{1}$. The incidence of cancer is increasing in the developing countries and in the under developed countries.At the same time, cancer mortality rates started to decline in some western countries due to reduction in smoking prevalence, improved early detection and advances in cancer therapy ${ }^{2}$.

The most common cancers seen in worldwide are: lung
$12.3 \%$, breast $10.4 \%$ and colorectal $9.4 \%{ }^{3}$ Populations in developing countries are vulnerable to cancers in which infectious agents play a significant role. They include cancers of the stomach, cervix, liver and esophagus. These cancers are largely attributed to differences in life style including dietary habits. ${ }^{1}$

India is a vast rural panorama with $70 \%$ of the population residing in villages in rural surroundings. Cancer statistics demonstrate that cancers frequently observed in India are lifestyle dependent, with offending factors such as tobacco usage, low socio-economic status, multiple pregnancies and poor sexual hygiene. These factors are closely related to the population living in rural surroundings and they are targets for cancer prevention ${ }^{4}$. Low socio economic status and low literacy rates are crucial factors that prevent patients from seeking treatment at an early stage and unfortunately most patients are diagnosed at an advanced stage of the disease. It is very difficult for these patients to achieve cure and they are always provided with only 
palliative care with much cost and morbidity. These facts indicate that the strategy for cancer control in India should be focused on health education about prudence in lifestyles and diets; symptomatology of early cancer; availability of screening programs for the high risk population; and education about the fact that early diagnosis and appropriate treatment are compatible with long term cancer free survival with minimum morbidity.

Currently, $50 \%$ of cancers are curable if detected early, $25 \%$ can be effectively palliated by treatment even in an advanced stage and for the remaining $25 \%$ good palliative care and pain relief can be achieved. In the new millennium, if appropriate steps are taken to address the problem in a pragmatic manner, by 2020, two thirds of cancers could be cured and only $5 \%$ of patients will need terminal care ${ }^{4}$

During clinical experience the researcher has come across many clients with advanced stage of disease where treatment would not help. Lot of money and time were spent by these clients for the complete cure but nothing would make them better. On the other hand researcher also found clients getting treatment in the very initial stage of cancer for which complete cure was achieved. Thus the researcher was encouraged to assess the knowledge on early symptoms of cancer particularly among the rural and urban women so as to create awareness which would further contribute to the detection of disease in the less advanced stage.

The objectives of this study were to: 1 . Identify the knowledge of rural and urban women on early symptoms of cancer. 2. Compare the level of knowledge on early symptoms of cancer among rural and urban women. 3. Find an association between the knowledge of rural and urban women on early symptoms of cancer and selected demographic variables.

It was hypothesized that (a) $\mathrm{H}_{1:}$ There will be a significant difference in the level of knowledge on early symptoms of cancer among rural and urban women. (b) $\mathrm{H}_{2}$ : There will be an association between the level of knowledge of rural and urban women on early symptoms of cancer and selected variables.

As a framework for understanding the knowledge on early symptoms, risk factors, etiology and diagnostic measures of cancer, the Health Belief Model by Becker is employed for the present study. Becker, et.al (1974) illustrates the main elements of perceived susceptibility and severity of the diseases, with regard to preventive health behavior and the perceived benefits and barriers to action ${ }^{4}$. The perceptions of the client are affected by modifying factors like demographic, socio-psychological and structural variables. The model also emphasizes the importance to cues to action or triggering mechanisms. Therefore, this model helps to explore the various factors affecting woman's knowledge in relation to cancer symptoms, etiology and diagnostic tests ${ }^{5}$

\section{Methods and Materials :}

An evaluative approach with descriptive cross sectional survey design was adopted for the study. The study was conducted in Natekal PHC (Rural area) which has a population of 20,000 and Jeppu Urban family welfare centre (Urban area) with a population of 40,000 .The sample consisted of 200 women, out of which 100 women were from urban area of Jeppu and 100 from rural area of Natekal PHC. Stratified Sampling technique was used for selection of the samples. The Natekal PHC was divided into different strata based on the anganwadi's working under the PHC. Female population of each anganwadis was taken and the proportionate samples were selected from both Jeppu UFWC and Natekal PHC. Jeppu UFWC had a total number of 19 anganwadi's and Natekal PHC had a total number of 23 anganwadis. The data was collected by a demographic pro forma and a knowledge questionnaire which had 23 multiple choice and 11 dichotomous or Yes/No questions. The knowledge was assessed on the following areas: Risk factors, etiology, signs and symptoms, Diagnostic measures and Prevention. A score value of (1) was allotted to each correct response. The total score was 78. The level of knowledge was arbitrarily scored classified as, Good (62-78), average (46-61) and poor (0-45).

Split half method was used to find out the reliability of the 
tool. The reliability was found to be 0.9 indicating high reliability of the tool. Further the tool was translated to Kannada and again retranslated to English to find out the correctness of the Kannada tool. Tool written in Kannada was used for the data collection in rural area and English tool was used in urban area. Pilot study was conducted in selected urban and rural area from $20^{\text {th }}$ July to $22^{\text {nd }}$ July, 2007 in order to check the feasibility and practicability of the study. Permission was obtained from District Health Officer Mangalore, concerned PHC Medical Officers prior to the data collection.After obtaining permission from the subjects; the investigator explained the purpose of the study and distributed the structured questionnaire to the subjects. The investigator read out each question with the help of Anganwadi teacher and asked the subject to mark the answer in the given space. After collecting back the answer sheet the investigator explained the answer of each question and provided clarifications of doubts. Data analysis was done to (1) Assess the knowledge of rural and urban women the data was analyzed by using both descriptive and inferential statistics. (2) Compare the level of knowledge independent sample t' test was used. (3) Find the association between the level of knowledge of rural and urban women with selected variables Chi-square test was used.

\section{Results and Discussion :}

The data analyzed were presented under the following headings

Section I:Description of sample characteristics. (Table -1) The findings in table 1 depict that majority of the subjects $123(61.5 \%)$ were between the age group of $20-29$ years, $100 \%$ were literates, $117(58.5 \%)$ subjects were married, $112(56 \%)$ were housewives, $103(51.5 \%)$ belonged to nuclear family and only 29(14.5) had a monthly income of more than Rs.10,000/-

\section{Section II:}

Level of knowledge of urban and rural women on early symptoms of Cancer- The present study shows that the rural women (53.6\%) had better knowledge regarding risk factors and etiology of cancer when compared to urban women (51.02\%). The Urban women (50\%) had better knowledge about diagnostic measures of cancer when compared to rural women (45.42). The knowledge regarding signs and symptoms shows that urban women (39.83\%) had better knowledge than rural women (36\%). $(57 \%)$ of the urban women and $(55 \%)$ of the rural women were aware about preventive measures of cancer. (Table 2). Supporting the above findings various studies conducted in Nigeria and London revealed a sobering picture of women's lack of knowledge regarding cancer. ${ }^{6,7}$

\section{Section III:}

Comparison of level of knowledge of rural and urban women on early symptoms of cancer: In the present study, the mean knowledge scores of urban women were found to be 38.26 and rural women were 34.79 and the mean difference was 3.47. The calculated t value, 2.054 was greater than the table value of 1.644. $(p<0.05)$ This finding signifies a significant difference in the knowledge of urban and rural women.(Table-3)

Supportive findings are seen in a study conducted in Mississippi in 2001 among rural residents of African American women which revealed that the rural residents were diagnosed at a later stage of the cancer disease compared to the urban residents ${ }^{.8}$

A study conducted in Texas has also revealed a larger proportion of cancers diagnosed at the pre-malignant stage for urban residents ${ }^{8}$. These findings suggest that rural cancer patient may be at disadvantage when compared to their urban counter parts which can be attributed to various factors like lack of resources, lack of awareness, socioeconomic factors etc.

\section{Section IV:}

Association between the level of knowledge and Selected demographic variables

In the present study, there was significant association between the age and level of knowledge of women $\left({ }^{x_{2}} \mathrm{cal}=\right.$ $17.597 \mathrm{p}<0.05)$. It is supported by a study conducted by Susan who revealed that there was a significant association between knowledge regarding early symptoms of cancer and the age of women. ${ }^{9}$ It is also supported by a study 
conducted in US which reported that there was significant association between knowledge and age. On the contrary a study conducted by Shambavi* revealed no significant association between knowledge and age. In the present study, there was a significant association between the educational status ( $\chi_{2}$ cal $=12.578, p<0.05$ ), occupational status ( $\chi_{2}$ cal $\left.=9.27, p<0.05\right)$ and the level of knowledge of women on cancer.

The present study findings revealed no significant association between the level of knowledge and the marital status ( $\left.\chi_{2} \mathrm{cal}=3.75, \mathrm{p}>0.05\right)$, religion $\left(\chi_{2} \mathrm{cal}=6.46\right.$, $p>0.05$ as well as the type of family $\left(\chi_{2} \mathrm{cal}=7.97, p>0.05\right)$. These findings are supported by a study conducted in Turkey which revealed no significant association between the level of knowledge and the marital status of women ( $\chi_{2}$ cal $=3.751, p>0.05)^{11}$ and a supportive study conducted by
Susan which revealed no significant association between knowledge and the type of family. ${ }^{9}$

The present study findings revealed no significant association between knowledge and the monthly income of family ( $\chi_{2}$ cal $\left.=8.029, p>0.05\right)$. These findings are supported by Shambavi's study which revealed no significant association between knowledge and the monthly income of the family (personal communication)*. On the contrary a study conducted among women in California also reported that lower income women were likely to be less knowledgeable than women with higher income

\section{Conclusion :}

Cancer is one of the leading causes of death in the world, particularly in developing countries. $40 \%$ of cancers are preventable and death can be avoided if detected at an

Table 1: Frequency and Percentage Distribution of sample according to the Demographic characteristics Urban Women $\left(n_{1}\right)=100$ Rural Women $\left(n_{2}\right)=100$

\begin{tabular}{|c|c|c|c|}
\hline Variables & $\begin{array}{c}\text { Urban } \\
\text { frequency }\end{array}$ & $\begin{array}{c}\text { Rural } \\
\text { frequency }\end{array}$ & $\begin{array}{c}\text { Mean } \\
\text { percentage }\end{array}$ \\
\hline \multicolumn{4}{|l|}{ Age (in years) } \\
\hline $20-29$ & 61 & 62 & 61.5 \\
\hline $30-39$ & 31 & 24 & 27.5 \\
\hline $40-49$ & 7 & 7 & 7 \\
\hline $50-60$ & 1 & 7 & 4 \\
\hline \multicolumn{4}{|l|}{ Educational status } \\
\hline Primary & 6 & 49 & 27.5 \\
\hline High school & 5 & 5 & 5 \\
\hline PUC & 56 & 27 & 41.5 \\
\hline Graduate \& above & 33 & 19 & 26 \\
\hline \multicolumn{4}{|l|}{ Marital status } \\
\hline Married & 65 & 52 & 58.5 \\
\hline Unmarried & 34 & 46 & 40 \\
\hline Widow & 1 & 2 & 1.5 \\
\hline \multicolumn{4}{|l|}{ Occupational status } \\
\hline Employed & 56 & 32 & 44 \\
\hline Housewives & 44 & 68 & 56 \\
\hline \multicolumn{4}{|l|}{ Type of family } \\
\hline Nuclear & 60 & 43 & 51.5 \\
\hline Joint family & 26 & 49 & 37.5 \\
\hline Extended family & 14 & 8 & 11 \\
\hline \multicolumn{4}{|l|}{$\begin{array}{l}\text { Monthly income of } \\
\text { family (in Rs.) }\end{array}$} \\
\hline$<2000$ & 16 & 36 & 26 \\
\hline $2000-5000$ & 31 & 26 & 28.5 \\
\hline $5,000-10,000$ & 30 & 32 & 31 \\
\hline$>10,000$ & 23 & 6 & 14.5 \\
\hline
\end{tabular}


Table 2: Area wise Distribution of Knowledge Regarding Early Symptoms of Cancer:

\begin{tabular}{|c|l|c|c|c|}
\hline Serial No. & Areas & $\begin{array}{c}\text { Maximum } \\
\text { Possible Scores }\end{array}$ & $\begin{array}{c}\text { Obtained } \\
\text { Mean Percentage } \\
\text { Knowledge } \\
\text { Score-Urban }\end{array}$ & $\begin{array}{c}\text { Obtained } \\
\text { Mean Percentage } \\
\text { Knowledge } \\
\text { Score-Rural }\end{array}$ \\
\hline 1 & Risk factors \& Etiology & 34 & 51.02 & 53.6 \\
\hline 2 & Diagnostic measures & 7 & 50.00 & 45.42 \\
\hline 3 & Signs \&symptoms & 31 & 39.83 & 36.00 \\
\hline 4 & Prevention & 6 & 57.00 & 55.00 \\
\hline
\end{tabular}

Table 3: Comparison of level of knowledge regarding early symptoms of cancer among urban and rural women.

\begin{tabular}{|l|c|c|c|c|c|c|}
\hline Variable & Mean & $\begin{array}{c}\text { Mean } \\
\text { Difference }\end{array}$ & SE(D) & "t" value & d.f & $\begin{array}{c}\text { Level } \\
\text { of } \\
\text { Significance }\end{array}$ \\
\hline Urban women & 38.26 & 3.47 & 1.69 & 2.054 & 198 & $\begin{array}{c}0.041 \\
P<0.05 \\
\text { Rural women }\end{array} 34.79$ \\
\hline
\end{tabular}

tab (198) at 5\% L.O.S $=1.644$

early stage. In India cancer related mortality is very high due to lack of awareness of the early symptoms and risk of cancer leading to delayed screening and increased exposure rate of the risk factors. Nurses play a significant role in the disease prevention and health promotion of

\section{References :}

1. WHO National Cancer control programs policies and managerial guidelines, WHO publication, $2^{\text {nd }}$ edition Geneva 2002

2 Mosnson. R, IARC Monographs on the evaluation of Carcinogenic risk to humans,Vol-178,Lyon,IARC Press,2004.

3 Bernard W. Stewart, World Cancer Report, Lyon, IARC Press 2003

4 Early detection of cancer in rural area-Report submitted to Cancer Aid and research foundation-Indian charitable organization, Dehradun, 2000.

5 Talbot L A. Principles and practice of nursing research. $2^{\text {nd }}$ ed. Philadelphia: Saunders;2002

6 O.Abimbola, Oluwatosin and O. Oladepo. Knowledge of breast cancer and its early detection measures among rural women in Akinyele local government area, Ibadan, Nigeria, Vol.6, BMC Cancer accessed from www.biomedcentral,26th Nov 2006
S= significant

patients with chronic illness. Educational programs on healthful living with cost effective and motivating teaching strategies can be undertaken for the community so as to curb the mortality and morbidity associated with cancer .

7 Scanlon K., An investigation into breast cancer related knowledge, beliefs and attitudes among women form minority ethnic group, London.2004.

8 Gosschalk A, Carossa S., Cancer in rural areas: A literature review, rural healthy people $2010 \mathrm{Vol} 2$ Texas dated 25/11/06 accessed from http:// www. medscape. Com

9 Susan et.al. Research and practice socio-cultural correlates of breast cancer knowledge and screening in Urban African women, vol 93.American Journal of Public health, 2003

*Shambavi., A study on effectiveness of self-instructional module on prevention and early detection of breast cancer among women from a selected rural area of Mangalore taluk, M. Sc Nursing thesis submitted to RGUHS, Karnataka, 2007 